\title{
Impacto do isolamento social durante a pandemia de COVID-19 na saúde mental da população: uma revisão integrativa da literatura
}

\author{
Impact of social isolation during the COVID-19 pandemic on the mental health of the population: an \\ integrative literature review
}

\author{
Carlos Felipe Batalha do Val ${ }^{1 *}$, Alex Andrei de Oliveira Fraga ${ }^{1}$, Bárbara Batista Silveira ${ }^{2}$ \\ Como citar esse artigo. VAL, C. F. B;

\section{Resumo}

FRAGA, A. A. O; SILVEIRA, B. B.

Impacto do isolamento social durante a pandemia de COVID-19 na saúde mental da população: uma revisão integrativa da literatura. Mosaico - Revista Multidisciplinar de Humanidades, Vassouras, v. 12 , n. 3, p. 30-40, set./ dez. 2021.

Estudos têm relatado que as medidas restritivas, como isolamento social e quarentena, durante a pandemia da COVID-19 configuram grande risco para a saúde mental das pessoas. Este estudo objetivou verificar qual é o impacto das medidas restritivas, de isolamento social e quarentena, na saúde mental dos indivíduos durante a pandemia de COVID-19. Foi realizada uma revisão integrativa de estudos publicados entre janeiro e dezembro de 2020, nos idiomas português e inglês, indexados nas bases de dados PubMed, Lilacs, Medline e SciELO, utilizando os descritores COVID 19, Isolamento social, Quarentena, Saúde Mental e Saúde Psicológica. Embora as medidas restritivas de saúde pública, como isolamento social e quarentena e/ ou lockdown sejam condutas essenciais para limitar a propagação viral da COVID-19, representam séria ameaça à saúde mental da população. Verifica-se que mulheres e adultos jovens são mais vulneráveis a essas medidas, apresentando níveis mais elevados de estresse, angústia, ansiedade e sintomas depressivos. Fatores socioeconômicos e nível educacional também têm significativa influência na saúde psicológica e mental das pessoas durante essas medidas: quanto menor a renda e o nível de escolaridade, maior é a incidência de sofrimento psicológico. Observa-se, ainda, a influência da mídia e das redes sociais no aumento da ansiedade, quando usadas durante mais tempo que o habitual. Existe a necessidade de iniciativas de saúde pública direcionadas para as implicações psicológicas decorrentes da pandemia da COVID-19 e consequentes medidas restritivas. Essas iniciativas devem ser pautadas levando-se em conta uma abordagem integral que considere as dimensões física, mental e social da população.

Palavras-chave: COVID 19; Isolamento social; Quarentena; Saúde Mental; Saúde Psicológica.

\begin{abstract}
Studies have reported that restrictive measures, such as social isolation and quarantine, during the COVID-19 pandemic have been configured as a great risk to people's mental health. This study aims to see what the impact of restrictive measures, social isolation and quarantine, have on individuals' mental health during the COVID-19 pandemic. An integrative review of studies published between January and December 2020, in Portuguese and English, indexed in the databases PubMed, Lilacs, Medline and SciELO, using the descriptors COVID 19, Social isolation, Quarantine, Mental Health and Psychological Health. While restrictive public health measures such as social isolation, quarantine and/or lockdown are essential to limit the viral spread of COVID-19, they pose a serious threat to the mental health of the population. Women and young adults are found to be more vulnerable to these measures, exhibiting higher levels of stress, distress, anxiety, and depressive symptoms. Socioeconomic factors and educational level also have influence significant on the psychological and mental health of people during these measures, the lower the income and education level, the higher the incidence of psychological distress. The influence of media and social networks in increasing anxiety is also observed, when used longer than usual. There is a need for public health initiatives directed at the psychological implications arising from the pandemic of COVID-19 and consequent restrictive measures. These initiatives should be guided by an integral approach that considers the physical, mental, and social dimensions of the population.
\end{abstract}

Keywords: COVID 19; Social Isolation; Quarantine; Mental Health; Psychological Health.

\section{Introdução}

Em dezembro de 2019 a Organização Mundial da Saúde (OMS) foi informada sobre a existência de um grupo de pacientes internados com um tipo de pneumonia de etiologia desconhecida na cidade de Wuhan, província de Hubei, na China. (SILVA; SANTOS; OLIVEIRA, 2020) Logo depois, no início de janeiro de 2020, após pesquisa realizada por cientistas chineses, descobriu-se que se tratava de uma infecção respiratória provocada por um novo coronavírus, o qual, a princípio, foi chamado de 2019-nCoV. E em fevereiro a OMS passa a denominá-lo de Sars-CoV-2, que significa "Coronavírus da Síndrome Respiratória Aguda Grave 2", e a infecção provocada por ele de "Doença Coronavírus 2019" (COVID-19). (AZIZI; ACHAK; ABOUDI et al., 2020; DU; MAYER; HUMMEL et al., 2020; PEREIRA; OLIVEIRA; COSTA et al., 2020)

Em 12 de janeiro, a OMS havia reconhecido oficialmente a sequência genética desse coronavírus,

Afiliação dos autores:

${ }^{1}$ Discente do Curso de Psicologia, Universidade de Vassouras, Vassouras, RJ, Brasil.

${ }^{2}$ Docente do Curso de Psicologia, Universidade de Vassouras, Vassouras, RJ, Brasil.

* Email de correspondência: cfbval2@gmail.com 
o que veio possibilitar o desenvolvimento de testes de diagnósticos baseados na reação em cadeia da polimerase - PCR (do inglês, polymerase chain reaction). (TORALES; O'HIGGINS; CASTALDELLIMAIA et al., 2020) No final de janeiro, já se constatava que a infecção estava se disseminando rapidamente de pessoa para pessoa, levando a OMS a declarar o surto da COVID-19 como uma emergência de saúde pública de interesse internacional. (AL-AJLOUNI; PARK; ALAWA et al., 2020)

Em 11 de março de 2020, devido à alta taxa de transmissão do vírus e ao aumento da sua propagação a nível global, a OMS declarou a COVID-19 uma pandemia. (PEREIRA; OLIVEIRA; COSTA et al., 2020; DELMASTRO; ZAMARIOLA, 2020) As pandemias são definidas como epidemias que se disseminam rapidamente por várias partes do mundo, acometendo um grande número de pessoas (DUARTE; SANTO; LIMA et al., 2020), sendo a COVID-19 uma pandemia viral que ainda está em andamento, onde as taxas de infecção, de mortalidade e outras estatísticas ainda estão em desenvolvimento. Conforme dados divulgados pela OMS, em 31 de dezembro de 2020 já havia 82.363.325 casos confirmados de COVID-19, com 1.803.123 mortes no mundo. (WHO, 2020)

No Brasil, o primeiro caso da doença foi notificado em 25 de fevereiro de 2020 (DUARTE; SANTO; LIMA et al., (2020), sendo registrada em 17 de março a primeira morte por COVID-19, de um homem idoso, de 62 anos, que estava internado em um hospital particular de São Paulo. (SILVA; SANTOS; OLIVEIRA, 2020) A partir daí, o número de pessoas acometidas pelo vírus no país cresceu rapidamente, registrando até o dia 31 de dezembro de 2020, segundo dados do Ministério da Saúde, 7.675.973 casos confirmados e 194.949 óbitos. (BRASIL, 2020)

O vírus da COVID-19 (Sars-CoV-2) é transmitido principalmente por meio de gotículas, podendo contaminar todas as pessoas próximas a um hospedeiro. (BURHAMAH; ALKHAYYAT; OROSZLÁNYOVÁ et al., 2020) Entre os sintomas físicos da doença, destacam-se tosse, febre e dificuldades respiratórias (SCHMIDT; CREPALDI; BOLZE et al., 2020), sendo referidos ainda outros sintomas clínicos como calafrios, coriza, dor de garganta, náuseas, vômitos e diarreia. Geralmente, as pessoas apresentam sintomas leves, como também tem pessoas assintomáticas, as quais não manifestam sintoma algum. (RODRÍGUEZREY; GARRIDO-HERNANSAIZ; COLLADO, 2020)

Algumas doenças pré-existentes têm sido associadas a um maior risco de mortalidade por COVID19, destacando-se o diabetes, a hipertensão e as doenças cardíacas. (TORALES; O'HIGGINS; CASTALDELLIMAIA et al., 2020) No entanto, outros fatores de risco também têm sido referidos, entre os quais destacam-se a obesidade e a idade mais avançada.
Cerca de $80 \%$ dos indivíduos infectados se recuperam facilmente da doença, sem que haja necessidade de tratamento específico. No entanto, aproximadamente um em cada seis casos da doença evolui para pneumonia grave, podendo levar à insuficiência respiratória, lesão cardíaca, síndrome do desconforto respiratório agudo e morte. (RODRÍGUEZREY; GARRIDO-HERNANSAIZ; COLLADO, 2020)

Nos primeiros meses da pandemia, devido ao elevado grau de contágio do Sars-CoV-2 e seus potenciais efeitos deletérios à saúde, bem como pela ausência de intervenções farmacológicas eficazes e seguras, tais como medicamentos ou vacinas (SCHMIDT; CREPALDI; BOLZE et al. 2020), governantes de diversos países, inclusive do Brasil, na tentativa de limitar a propagação do vírus e evitar o colapso dos sistemas de saúde, impuseram diferentes medidas de saúde pública, desde recomendações de distanciamento físico e confinamento domiciliar, até paralisação total das atividades não essenciais e bloqueios de rodovias e aeroportos. (BENKE; AUTENRIETH; ASSELMANN et al., 2020; FIORILLO; SAMPOGNA; GIALLONARDO et al., 2020; NOVOTNÝ; GONZALEZ-RIVAS; KUNZOVÁ et al., 2020)

Embora essas medidas sejam eficazes para limitar a transmissão viral e minimizar o contato com pessoas infectadas, dependendo do seu tempo de duração podem ter efeitos graves no bem-estar social e na economia em geral. (AL-AJLOUNI; PARK; ALAWA et al., 2929; CASAGRANDE; FAVIERI; TAMBELLI et al., 2020) Assim, fora o enorme impacto causado na saúde pública, o efeito da COVID-19 na sociedade tem sido significativo, alterando consideravelmente o cotidiano de vida das pessoas (BENKE; AUTENRIETH; ASSELMANN et al., 2020), afetando todos os extratos sociais, tanto a vida individual quanto coletiva, com repercussões enormes na esfera da saúde mental. (LIMA, 2020)

Nesse sentido, desde o início da pandemia, a OMS vem alertando sobre os efeitos da doença no bemestar psicológico da população. (EVERY-PALMER; JENKINS; GENDALL et al., 2020) Além disso, estudos realizados em diversos países, com o intuito de investigar as repercussões da pandemia da COVID-19 para a saúde mental, vêm revelando que ela tem causado sofrimento psicológico perceptível. (BURHAMAH; ALKHAYYAT; OROSZLÁNYOVÁ et al., 2020)

E nível individual, é revelado que durante as medidas de distanciamento e isolamento social podem ocorrer aumento significativo de quadros depressivos, ansiedade, estresse pós-traumático, medo, pânico e insônia, não apenas na população diretamente afetada pelo vírus, mas também na população em geral. (CASAGRANDE; FAVIERI; TAMBELLI et al., 2020) Verificou-se, ainda, a possibilidade de exacerbarem a depressão e a ansiedade pré-existentes, com efeitos 
deletérios expressivos sobre aquelas pessoas que já têm a saúde mental comprometida. (EVERYPALMER; JENKINS; GENDALL et al., 2020) E em nível coletivo, essas medidas estão associadas a uma série de adversidades psicossociais, incluindo, entre outras, dificuldades econômicas e violência doméstica. (FIORILLO; SAMPOGNA; GIALLONARDO et al., 2020; WATHELET; DUHEM; VAIVA et al., 2020)

Nessa perspectiva, a maioria dos estudos sugere que, além do cuidado com a saúde física é fundamental que se dê atenção também às consequências psicológicas e psiquiátricas associadas à pandemia da COVID-19, uma vez que o isolamento social, as atividades sociais restritas e o contato com as notícias divulgadas pelas diversas mídias podem desencadear uma série de transtornos de ordem psiquiátrica e/ou psicológica. (BURHAMAH; ALKHAYYAT; OROSZLÁNYOVÁ et al., 2020; BENKE; AUTENRIETH; ASSELMANN et al., 2020; LIMA, 2020; GUPTA; SAHOO; MEHRA et al., 2020) Inclusive, já foi levantada a hipótese de que essas circunstâncias podem levar a adoção de um comportamento de risco extremo, envolvendo inclusive tendências suicidas, indicando que o isolamento social e a solidão são fatores de risco reconhecidos para tentativas de suicídio. (PANDEY; BANSAL; GOYAL et al., 2020)

De acordo com estudo realizado na Espanha, existem evidências de que os efeitos psicológicos de surtos de infecção podem ser sentidos por meses ou até anos após esses eventos; portanto, uma melhor compreensão do impacto psicológico da pandemia da COVID-19 é fundamental para que se possa pôr em prática estratégias de enfrentamento que possam mitigar essas respostas durante a pandemia. (GARCÍAÁLVAREZ; DE LA FUENTE-TOMÁS; GARCÍAPORTILLA et al., 2020)

Diante do exposto, este estudo verificou qual foi o impacto das medidas restritivas, como isolamento social e quarentena, na saúde mental dos indivíduos durante a pandemia de COVID-19. Como também verificou a prevalência de sofrimento psicológico entre a população em geral; e quais medidas podem ser utilizadas para amenizá-lo. Consequentemente, a questão que se busca responder com este estudo é a seguinte: "Qual é o impacto das medidas de isolamento social na saúde mental dos indivíduos durante a pandemia da COVID19?".

Em termos teórico-metodológicos trata-se de uma revisão integrativa de literatura, realizada com artigos científicos nacionais e estrangeiros que tratam sobre o tema em pauta, publicados no ano de $2020 \mathrm{em}$ meio eletrônico.

Tendo em vista a importância do tema aqui tratado, considera-se que este estudo poderá contribuir para uma melhor compreensão sobre o sofrimento psicológico que afeta as pessoas neste momento de pandemia, além de contribuir para futuras pesquisas acadêmicas na área da Psicologia.

\section{Material e Método}

O método de pesquisa aplicado foi uma Revisão Integrativa de Literatura por meio de pesquisa realizada nas bases de dados PubMed, Lilacs, Medline e SciELO a procura de estudos relevantes em relação ao tema, publicados entre janeiro a dezembro de 2020 .

O estudo baseou-se em seis etapas para a sua elaboração, as quais incluíram: definição da questão norteadora, estabelecimento dos critérios de inclusão e exclusão, definição das informações a serem extraídas dos estudos, levantamento e seleção dos artigos relativos ao tema, avaliação dos estudos incluídos, interpretação dos resultados e síntese dos dados.

Foram utilizados os seguintes descritores de pesquisa combinados entre si por operadores booleanos: COVID 19 OR SARS-CoV-2 OR Síndrome respiratória aguda grave coronavírus 2 AND Isolamento social OR Confinamento domiciliar, OR Lockdown AND Saúde Mental OR Saúde Psicológica. Os critérios de inclusão para a seleção dos artigos foram: artigos publicados de janeiro a dezembro de 2020 nos idiomas português e inglês. Foram excluídos artigos que não se enquadravam ao tema da pesquisa e artigos duplicados nas bases de dados.

\section{Resultados}

Na primeira fase da busca, um total de 560 artigos foram encontrados nas bases de dados; após a aplicação dos critérios de inclusão e exclusão e a avaliação quanto a elegibilidade foram incluídos neste estudo três artigos da SciELO, seis da Medline, três da Lilacs e dezesseis da PubMed, perfazendo um total de 28 artigos, conforme apresentado na figura 1 .

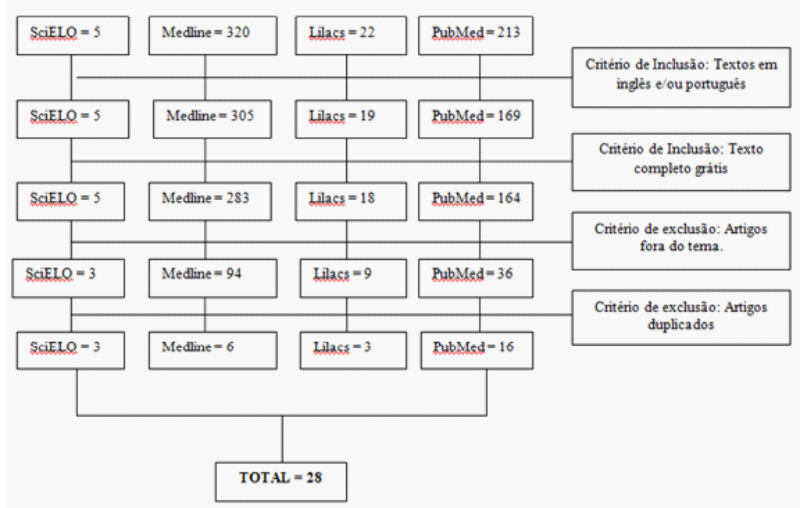

Figura 1. Resultado da busca bibliográfica nas bases de dados. 
Verifica-se que 23 artigos utilizaram metodologia transversal, com exceção do estudo realizado por Silva, Santos e Oliveira (2020) (Estudo Reflexivo) e as revisões de literatura realizadas por Pereira, Oliveira, Costa et al. (2020), Torales, O'Higgins, CastaldelliMaia et al. (2020), Schmidt, Crepaldi, Bolze et al. (2020) e Lima (2020).

Os estudos transversais foram realizados em diversos países, envolvendo, Europa, Ásia, África e Américas. As amostras foram recrutadas principalmente por meio da mídia social online. Os pesquisadores usaram vários tipos de questionários como instrumentos de pesquisa e uma variedade de instrumentos de avaliação.

No Quadro 1 são listados os estudo que utilizaram metodologia transversal, sendo compilados os seguintes dados: autor; país onde foi realizada a pesquisa; fonte de dados utilizada e quantitativo da amostra (total de participantes de cada estudo); instrumentos de avaliação utilizados na pesquisa para verificar o nível de sofrimento psicológico; e principais impactos do isolamento social, quarentena e/ou lockdown na saúde mental encontrados pelos pesquisadores.

\section{Discussão}

Embora as medidas restritivas de saúde pública, como isolamento social, quarentena e/ou lockdown sejam condutas essenciais para reduzir a propagação viral, elas representam um grande desafio para o bemestar geral da população. (FERNÁNDEZ; CRIVELLI;

Quadro 1. Características dos estudos transversais publicados no ano de 2020 sobre o impacto do isolamento social decorrente da pandemia da COVID-19 na saúde mental.

\begin{tabular}{|c|c|c|c|c|c|}
\hline AUTORES & PAÍS & $\begin{array}{c}\mathbf{N}^{\circ} \mathrm{DE} \\
\text { PARTICIPANTES }\end{array}$ & $\begin{array}{l}\text { FONTE DE } \\
\text { DADOS }\end{array}$ & $\begin{array}{c}\text { INSTRUMENTOS DE } \\
\text { AVALIAÇÃO }\end{array}$ & PRINCIPAIS IMPACTOS \\
\hline $\begin{array}{l}\text { Azizi et al. } \\
\quad(2020)\end{array}$ & Marrocos & 537 & $\begin{array}{l}\text { Pesquisa online } \\
\text { (9 a } 30 \text { de maio } \\
\text { de } 2020)\end{array}$ & $\begin{array}{l}\text { Questionário de Qualida- } \\
\text { de de Vida - EQ-5D-5L }\end{array}$ & $\begin{array}{l}\text { As mulheres apresentaram mais } \\
\text { problemas de mobilidade, dor/ } \\
\text { desconforto e ansiedade / depres- } \\
\text { são em comparação com os ho- } \\
\text { mens }\end{array}$ \\
\hline Du et al. (2020) & China & $\begin{array}{l}687 \text { (profissionais } \\
\text { diversos) }\end{array}$ & $\begin{array}{l}\text { Pesquisa online } \\
\text { (19 de março a } 7 \\
\text { de abril de } 2020)\end{array}$ & $\begin{array}{l}\text { Escala de Depressão, } \\
\text { Ansiedade e Estresse } \\
\text { (DASS-21) } \\
\text { Escala de Estresse Perce- } \\
\text { bido (PSS-14) }\end{array}$ & $\begin{array}{c}\text { Sintomas elevados de depressão, } \\
\text { ansiedade e estresse na popula- } \\
\text { ção em geral durante os estágios } \\
\text { finais do lockdown. }\end{array}$ \\
\hline $\begin{array}{l}\text { Al-Ajlouni et al. } \\
\qquad(2020)\end{array}$ & Jordânia & 1.240 & $\begin{array}{l}\text { Pesquisa online } \\
\text { (últimas } 2 \text { sema- } \\
\text { nas de março de } \\
\text { 2020). }\end{array}$ & $\begin{array}{l}\text { Escala de Transtorno de } \\
\text { Ansiedade Generalizada } \\
\text { (GAD-7). } \\
\text { Índice de Qualidade do } \\
\text { Sono de Pittsburgh. } \\
\text { Escala do Center for Epi- } \\
\text { demiological Studies - } \\
\text { Depression (CES-D). }\end{array}$ & $\begin{array}{l}\text { Aumento dos sintomas depressi- } \\
\text { vos e ansiedade os quais foram as- } \\
\text { sociados a resultados ruins de saú- } \\
\text { de do sono durante o lockdown }\end{array}$ \\
\hline $\begin{array}{l}\text { Delmastro; Za- } \\
\text { mariola (2020) }\end{array}$ & Itália & 6.692 & $\begin{array}{l}\text { Pesquisa online } \\
\text { (4 a } 19 \text { de junho } \\
\text { de } 2020) \text {. }\end{array}$ & $\begin{array}{l}\text { Short Mood and Feelings } \\
\text { Questionnaire (SMFQ). }\end{array}$ & $\begin{array}{l}\text { Escores mais altos de sintomas } \\
\text { depressivos indicativos de humor } \\
\text { depressivo em mulheres, adultos } \\
\text { mais jovens, pessoas que relata- } \\
\text { ram incerteza profissional e status } \\
\text { socioeconômico mais baixo. }\end{array}$ \\
\hline $\begin{array}{l}\text { Duarte et al. } \\
\quad(2020)\end{array}$ & $\begin{array}{l}\text { B R A S I L } \\
\text { (Rio G. do } \\
\text { Sul) }\end{array}$ & 799 & $\begin{array}{l}\text { Pesquisa online } \\
\text { (8 a } 23 \text { de abril } \\
\text { de } 2020)\end{array}$ & $\begin{array}{l}\text { Self-Report Questionnai- } \\
\text { re (SRQ-20) }\end{array}$ & $\begin{array}{l}\text { Ter renda diminuída no período, } \\
\text { fazer parte do grupo de risco e } \\
\text { estar mais exposto a informações } \\
\text { sobre mortos e infectados, são fa- } \\
\text { tores que podem provocar maior } \\
\text { prejuízo na saúde mental }\end{array}$ \\
\hline $\begin{array}{l}\text { Burhamah et al. } \\
\qquad(2020)\end{array}$ & Kuwait & 4.132 & $\begin{array}{l}\text { Pesquisa online } \\
\text { (25 a } 30 \text { de maio } \\
\text { de } 2020) \text {. }\end{array}$ & $\begin{array}{l}\text { Questionário de Saúde do } \\
\text { Paciente (PHQ-9). } \\
\text { Escala de Transtorno de } \\
\text { Ansiedade Generalizada } \\
\text { (GAD-7). }\end{array}$ & $\begin{array}{l}\text { Níveis mais elevados de depres- } \\
\text { são e ansiedade entre a população } \\
\text { mais jovem. }\end{array}$ \\
\hline
\end{tabular}


Quadro 1 (cont.). Características dos estudos transversais publicados no ano de 2020 sobre o impacto do isolamento social decorrente da pandemia da COVID19 na saúde mental.

\begin{tabular}{|c|c|c|c|c|c|}
\hline AUTORES & PAÍS & $\begin{array}{c}\mathrm{N}^{\circ} \mathrm{DE} \\
\text { PARTICIPANTES }\end{array}$ & $\begin{array}{l}\text { FONTE DE } \\
\text { DADOS }\end{array}$ & $\begin{array}{c}\text { INSTRUMENTOS DE } \\
\text { AVALIAÇÃO }\end{array}$ & PRINCIPAIS IMPACTOS \\
\hline $\begin{array}{l}\text { Rodríguez-Rey } \\
\text { et al. (2020) }\end{array}$ & Espanha & 3.055 & $\begin{array}{l}\text { Pesquisa online } \\
\text { (17 a } 24 \text { de mar- } \\
\text { ço de } 2020) \text {. }\end{array}$ & 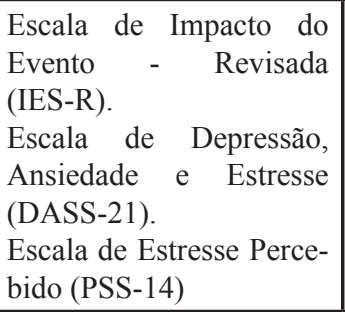 & $\begin{array}{l}\text { Mais de um terço da população } \\
\text { pesquisada apresentou sintomas } \\
\text { de impacto psicológico moderado } \\
\text { ou grave. O nível de saúde perce- } \\
\text { bido foi negativamente associado } \\
\text { ao impacto psicológico, estresse, } \\
\text { ansiedade e sintomas de depres- } \\
\text { são. }\end{array}$ \\
\hline $\begin{array}{l}\text { Benke et al. } \\
\text { (2020) }\end{array}$ & Alemanha & 4335 & $\begin{array}{l}\text { Pesquisa online } \\
\text { (17 de abril e } \\
15 \text { de maio de } \\
2020) .\end{array}$ & $\begin{array}{l}\text { Questionário de Saúde do } \\
\text { Paciente - 9 (PHQ-9). } \\
\text { Escala de Transtorno de } \\
\text { Ansiedade Generalizada } \\
\text { (GAD-7). } \\
\text { Manual Diagnóstico e } \\
\text { Estatístico de Transtornos } \\
\text { Mentais (DSM-5 CIDI). } \\
\text { Escala de Solidão UCLA } \\
\text { Versão 3. }\end{array}$ & $\begin{array}{l}\text { Um nível mais alto de restrições } \\
\text { estava associado a mais solidão, } \\
\text { maior sofrimento psicossocial e } \\
\text { menor satisfação com a vida. }\end{array}$ \\
\hline $\begin{array}{l}\text { Fiorillo et al. } \\
\qquad(2020)\end{array}$ & Itália & 20.720 & $\begin{array}{l}\text { Pesquisa online } \\
\text { (março a maio de } \\
\text { 2020) }\end{array}$ & $\begin{array}{l}\text { Escala de Depressão, } \\
\text { Ansiedade e Estresse } \\
\text { (DASS-21). } \\
\text { Questionário de Saúde } \\
\text { Geral (QSG-12). } \\
\text { Inventário de Obsessões } \\
\text { e Compulsões Revisado } \\
\text { (OCI-R). } \\
\text { Escala de Atributos de } \\
\text { Ideação Suicida (SI- } \\
\text { DAS). Impacto de } \\
\text { Escala de IES). } \\
\text { Evento (IES) } \\
\text { Escala de solidão UCLA. } \\
\text { Questionário Brief-CO- } \\
\text { PE. } \\
\text { Inventário de Cresci- } \\
\text { mento Pós-Traumático } \\
\text { (PTGI). }\end{array}$ & $\begin{array}{l}\text { Independente das características } \\
\text { sociodemográficas, os níveis de } \\
\text { ansiedade, sintomas depressivos } \\
\text { e de estresse aumentaram com o } \\
\text { tempo, sendo mais graves nas últi- } \\
\text { mas semanas do Lockdown. }\end{array}$ \\
\hline $\begin{array}{l}\text { Novotný et al. } \\
\text { (2020) }\end{array}$ & $\begin{array}{l}\text { República } \\
\text { Tcheca }\end{array}$ & 715 & $\begin{array}{l}\text { Pesquisa online } \\
(24 \text { de abril a } \\
27 \text { de maio de } \\
2020) .\end{array}$ & $\begin{array}{l}\text { Escala de Estresse Per- } \\
\text { cebido (Perceived Stress } \\
\text { Scale - PSS) } \\
\text { Questionário de Saúde do } \\
\text { Paciente (PHQ) }\end{array}$ & $\begin{array}{l}\text { Aumento significativo nos níveis } \\
\text { de estresse e na gravidade dos sin- } \\
\text { tomas depressivos. }\end{array}$ \\
\hline $\begin{array}{l}\text { Casagrande et } \\
\text { al. (2020) }\end{array}$ & Itália & 2.291 & $\begin{array}{l}\text { Pesquisa online } \\
\text { (18 de março a } 2 \\
\text { de abril de } 2020) \text {. }\end{array}$ & $\begin{array}{l}\text { Escala de Transtorno de } \\
\text { Ansiedade Generalizada } \\
\text { (GAD-7). } \\
\text { Questionário Geral de } \\
\text { Bem-Estar Psicológico } \\
\text { (PGWB). } \\
\text { Índice de Qualidade } \\
\text { do Sono de } \\
\text { (PSittsburgh } \\
\text { Inventário de } \\
\text { dade para o DSM-5 }\end{array}$ & $\begin{array}{l}57,1 \% \text { dos entrevistados experi- } \\
\text { mentaram má qualidade do sono, } \\
32,1 \% \text { tiveram altos níveis de sin- } \\
\text { tomas de ansiedade generalizada, } \\
41,8 \% \text { experimentaram sofrimen- } \\
\text { to psicológico e } 7,6 \% \text { sintomato- } \\
\text { logia relevante de transtorno de } \\
\text { estresse pós-traumático (TEPT). }\end{array}$ \\
\hline $\begin{array}{l}\text { Every-Palmer et } \\
\text { al. (2020) }\end{array}$ & $\begin{array}{l}\text { Nova Zelân- } \\
\text { dia }\end{array}$ & 2.416 & $\begin{array}{l}\text { Pesquisa online } \\
\text { (15 a } 18 \text { de abril } \\
\text { de } 2020)\end{array}$ & $\begin{array}{l}\text { Escala de Kessler (K10). } \\
\text { Escala de Transtorno de } \\
\text { Ansiedade Generalizada } \\
\text { (GAD-7). } \\
\text { Índice de Bem-Estar } 5 \text { da } \\
\text { Organização Mundial da } \\
\text { Saúde (OMS-5) }\end{array}$ & $\begin{array}{l}\text { Aumento de Ansiedade moderada } \\
\text { a grave em ambos os gêneros. Ní- } \\
\text { vel elevado de angústia em adultos } \\
\text { com menos de } 44 \text { anos. Aumento } \\
\text { nas taxas de violência familiar. }\end{array}$ \\
\hline
\end{tabular}


Quadro 1 (cont.). Características dos estudos transversais publicados no ano de 2020 sobre o impacto do isolamento social decorrente da pandemia da COVID19 na saúde mental.

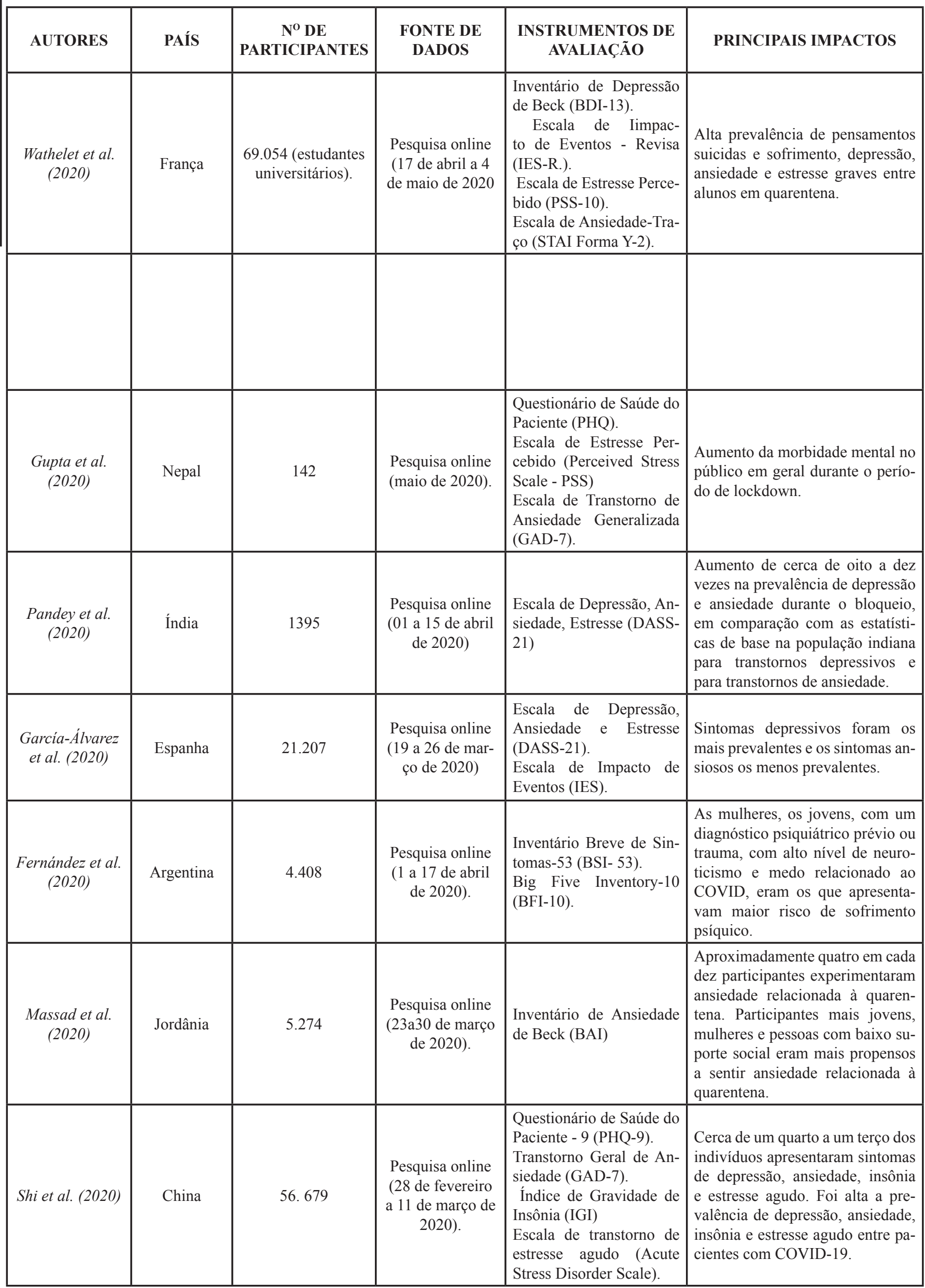


Quadro 1 (cont.). Características dos estudos transversais publicados no ano de 2020 sobre o impacto do isolamento social decorrente da pandemia da COVID19 na saúde mental.

\begin{tabular}{|c|c|c|c|c|c|}
\hline AUTORES & PAÍS & $\begin{array}{c}\mathrm{N}^{\circ} \mathrm{DE} \\
\text { PARTICIPANTES }\end{array}$ & $\begin{array}{l}\text { FONTE DE } \\
\text { DADOS }\end{array}$ & $\begin{array}{c}\text { INSTRUMENTOS DE } \\
\text { AVALIAÇÃO }\end{array}$ & PRINCIPAIS IMPACTOS \\
\hline $\begin{array}{l}\text { Roma et al. } \\
\text { (2020) }\end{array}$ & Itália & 439 & $\begin{array}{l}\text { Pesquisa online } \\
\text { (28 de abril a } \\
3 \text { de maio de } \\
\text { 2020). }\end{array}$ & $\begin{array}{l}\text { Escala de Depressão, } \\
\text { Ansiedade e Estresse } \\
\text { (DASS-21). } \\
\text { Inventário de Personali- } \\
\text { dade para o DSM-5. } \\
\text { Formulário Breve - } \\
\text { Adulto (PID-5-BF) }\end{array}$ & $\begin{array}{l}\text { Aumento nos níveis de estresse e } \\
\text { depressão, mas nenhum aumento } \\
\text { na ansiedade. }\end{array}$ \\
\hline $\begin{array}{l}\text { Yamamoto et al. } \\
\text { (2020) }\end{array}$ & Japão & 11.333 & $\begin{array}{l}\text { Pesquisa online } \\
\text { (11 de maio a } \\
12 \text { de maio de } \\
\text { 2020). }\end{array}$ & $\begin{array}{l}\text { Escala de Kessler (K6). } \\
\text { Questionário de Saúde } \\
\text { do Paciente (Patient He- } \\
\text { alth Questionnaire-9 - } \\
\text { PHQ-9). } \\
\text { Escala de Solidão da } \\
\text { UCLA }\end{array}$ & $\begin{array}{l}\text { Aumento do sofrimento mental } \\
\text { traduzido em angústia e sintomas } \\
\text { de depressão. }\end{array}$ \\
\hline Bu et al. (2020) & Reino Unido & 38.217 & $\begin{array}{l}\text { Pesquisa online } \\
\text { (23 de março a } \\
10 \text { de maio de } \\
\text { 2020). }\end{array}$ & $\begin{array}{l}\text { Escala de Solidão UCLA } \\
\text { Versão } 3 . \\
\text { Escala de Suporte Social } \\
\text { Percebido (F-SozU K-6). }\end{array}$ & $\begin{array}{l}\text { Os níveis percebidos de solidão } \\
\text { eram relativamente estáveis no } \\
\text { Reino Unido, mas para muitas } \\
\text { pessoas, esses níveis eram altos, } \\
\text { sem sinais de melhora. }\end{array}$ \\
\hline $\begin{array}{l}\text { Smith et al. } \\
\quad \text { (2020) }\end{array}$ & EUA & 278 & $\begin{array}{l}\text { Pesquisa online } \\
\text { (16 de abril e } \\
9 \text { de maio de } \\
\text { 2020). }\end{array}$ & $\begin{array}{l}\text { Escala de Depressão, An- } \\
\text { siedade, Estresse (DASS- } \\
21 \text { ). } \\
\text { Questionário de avaliação } \\
\text { (VQ) } \\
\text { Índice de Bem-Estar } 5 \text { da } \\
\text { Organização Mundial da } \\
\text { Saúde (OMS-5). } \\
\text { Escala de Amiza - (Frien- } \\
\text { dship Scale - Hawthorne, } \\
\text { 2006). } \\
\text { Questionário de Aceita- } \\
\text { ção e Acão II (AAQ-2). } \\
\text { Questionário de regula- } \\
\text { ção emocional (ERQ). } \\
\text { Escala de intolerância à } \\
\text { incerteza (IUS-12). }\end{array}$ & $\begin{array}{l}\text { A relação entre isolamento social } \\
\text { e sofrimento psicológico foi mo- } \\
\text { derada tanto pela inflexibilidade } \\
\text { psicológica quanto pela intole- } \\
\text { rância à incerteza. Em ambos os } \\
\text { casos, níveis mais altos de isola- } \\
\text { mento social foram relacionados a } \\
\text { piores resultados de saúde mental, } \\
\text { e a força dessas relações aumen- } \\
\text { tou entre os participantes à medida } \\
\text { que os níveis dos moderadores au- } \\
\text { mentaram (baixo, médio, alto). }\end{array}$ \\
\hline
\end{tabular}

GUIMET et al., 2020) São experiências desagradáveis para a grande maioria das pessoas, originando sensação de tédio, insegurança e incerteza sobre a doença e o sobre o futuro, caracterizando-se como uma séria ameaça à saúde mental. (FIORILLO; SAMPOGNA; GIALLONARDO et al., 2020; MASSAD; AL-TAHER; MASSAD et al., 2020)

Estima-se que em situações de pandemia, de um terço a cinquenta por cento da população venha a apresentar consequências psicológicas e psiquiátricas caso não recebam os cuidados adequados, ultrapassando, inclusive, o número de pessoas acometidas pela infecção. (LIMA, 2020)

Diferentemente de outras epidemias e pandemias que já aconteceram no século XXI, como a Síndrome Respiratória Aguda Grave (SARS) e a Síndrome Respiratória do Oriente Médio (MERS), a COVID-
19 é considerada a síndrome respiratória viral mais contagiosa e mais severa desde a pandemia de influenza H1N1, ocorrida em 1918, também conhecida como gripe espanhola, a qual levou a óbito milhares de pessoas no mundo. (SCHMIDT; CREPALDI; BOLZE et al., 2020; SHI; LU; QUE et al., 2020)

Por si só, a pandemia da COVID-19 tem sido motivo para impactar negativamente o estado psicológico das pessoas, uma vez que as preocupações relacionadas à morbidade e mortalidade da doença podem ter um enorme impacto na saúde psicológica e mental. (PANDEY; BANSAL; GOYAL et al., 2020)

Além do medo da infecção e pelo fato de ser uma doença ainda pouco conhecida e com um prognóstico incerto, devido à transmissão do vírus ocorrer mediante contato pessoal, onde familiares são geralmente recomendados a se distanciar de seus 
parentes diagnosticados com COVID-19, como forma de evitar o contágio, isso pode gerar sentimentos de incapacidade e de frustração. (PEREIRA; OLIVEIRA; COSTA et al., 2020) Estudo realizado na China mostrou que aproximadamente $50 \%$ dos familiares ou amigos de pacientes com COVID-19 apresentaram sintomas de saúde mental leves a graves. (SHI; LU; QUE et al., 2020)

As impossibilidades de confortar ou cuidar de membros da família, de ter a chance de estar com os seus entes queridos quando a doença se agrava ou culmina em óbito e de poder se despedir ou de organizar um funeral, tem representado uma carga psicológica significativa para essas pessoas. (DU; MAYER; HUMMEL et al., 2020; PEREIRA; OLIVEIRA; COSTA et al., 2020)

Da mesma forma, as medidas restritivas, como a quarentena e o distanciamento social, colocadas em prática na maioria dos países, até então desconhecidas por grande parte da população mundial, trouxeram diversos desafios. Observa-se, por exemplo, que desde que essas medidas começaram a ser implantadas vivenciase, como resultado, questões sociais e econômicas graves, como desemprego, perda de renda, pessoas com dificuldades de suprir suas necessidades básicas, como alimentação e moradia, as quais também são situações que têm contribuído para impactar significativamente a saúde mental das pessoas.

Nesse sentido, vários estudos reportam que o distanciamento de familiares, as oportunidades de atividades recreativas limitadas, a impossibilidade de frequentar escolas e universidades, com o estudo e o trabalho à distância (home office), bem como o aumento do desemprego e a insegurança financeira têm causado implicações sérias na saúde mental da população. (DU; MAYER; HUMMEL et al., 2020; NOVOTNÝ; GONZALEZ-RIVAS; KUNZOVÁ et al., 2020; EVERYPALMER; JENKINS; GENDALL et al., 2020)

Cita-se ainda a existência de alguns fatores de risco que podem contribuir para aumentar o impacto da pandemia e do isolamento social na saúde mental. Foi observado, em um estudo realizado no Brasil, uma maior inclinação para sofrimento mental entre pessoas adultas mais jovens, do sexo feminino, com histórico prévio de transtorno mental, que faziam parte do grupo de risco, como também entre aquelas que tiveram a renda reduzida ou que estavam mais expostas às informações sobre mortos e infectados. (DUARTE; SANTO; LIMA et al., 2020)

Outros estudos revelam também níveis mais elevados de ansiedade e depressão entre pessoas que passavam mais tempo seguindo noticiários sobre a COVID-19, acontecendo o mesmo com aquelas que gastavam mais tempo que o habitual usando a Internet a procura de informações sobre a doença. (AZIZI; ACHAK; ABOUDI et al., 2020; BURHAMAH; ALKHAYYAT; OROSZLÁNYOVÁ et al., 2020;
FIORILLO; SAMPOGNA; GIALLONARDO et al., 2020) Para Du, Mayer, Hummel et al. (2020) embora na Internet se possa encontrar elementos de apoio emocional, como telemedicina para pacientes com COVID-19, educação em saúde e aconselhamento em saúde mental, a sua exposição em excesso parece desempenhar papel importante nos problemas de saúde mental durante a pandemia.

Estudos enfatizam o poder das redes sociais e a necessidade de direcionar essas ferramentas na conscientização e na promoção da educação (BURHAMAH; ALKHAYYAT; OROSZLÁNYOVÁ et al., 2020), bem como a necessidade de os profissionais de mídia estarem adequadamente treinados, de forma que sejam capazes de fornecer informações imparciais e menos sensacionalistas nas situações catastróficas como esta que se vivencia atualmente. (FIORILLO; SAMPOGNA; GIALLONARDO et al., 2020)

Estudos revelam existir, ainda, grande possibilidade de aumento na incidência de números clinicamente relevantes de pessoas que venham a se envolver em comportamentos prejudiciais, como suicídio, por exemplo. (DELMASTRO; ZAMARIOLA, 2020) Estudo realizado na França com estudantes universitários mostrou que o isolamento social e as medidas de restrições foram responsáveis por elevados níveis de sofrimento psicológico, incluindo alta prevalência de pensamentos suicidas, ansiedade, depressão e estresse. (WATHELET; DUHEM; VAIVA et al., 2020)

Novotný, Gonzalez-Rivas e Kunzová et al. (2020) verificaram que o isolamento social resultou em um aumento significativo nos níveis de estresse e nos sintomas depressivos da população, afetando principalmente a saúde mental de mulheres e de pessoas adultas mais jovens. Os autores sugerem que a maior incidência de sofrimento psicológico entre as pessoas adultas mais jovens possivelmente esteja associada com preocupações com estudos, segurança no trabalho e estabilidade financeira.

Esses dados corroboram com estudos realizados no Kuwait e na Nova Zelândia, onde foi observado que pessoas mais idosas, bem como aquelas já aposentadas, apresentaram menor probabilidade de sofrer impacto psicológico devidoao lockdown quando comparadas com aquelas mais jovens. (BURHAMAH; ALKHAYYAT; OROSZLÁNYOVÁ et al., 2020; EVERY-PALMER; JENKINS; GENDALL et al., 2020)

Foi observado por Roma, Monaro, Colasanti et al. (2020), em estudo realizado na Itália, que história de situações estressantes, histórico de problemas de saúde e ter um parente com COVID-19 foram fatores associados à ansiedade e ao aumento da depressão entre a população em geral durante o lockdown, sendo também encontrada associação entre a faixa etária jovem e um maior nível de estresse. 
Estudo realizado no Japão constatou que o impacto do lockdown foi particularmente maior entre os profissionais de saúde e entre as pessoas com histórico de tratamento para transtornos psiquiátricos e adultos jovens. (YAMAMOTO; UCHIUMI; SUZUKI et al., 2020) Benke, Autenrieth, Asselmann et al. (2020) constataram também, em estudo realizado na Alemanha, maior sofrimento mental entre pessoas que estavam fazendo e/ou já haviam feito uso de tratamento psicoterápico ou psiquiátrico.

Massad, Al-Taher, Massad et al. (2020) verificaram, em estudo realizado na Jordânia, que cerca de $40 \%$ da população estudada experimentou algum grau de ansiedade relacionada com a quarentena. Entre os fatores de risco significativos correlacionados com níveis mais elevados de ansiedade destacaram o sexo feminino, a falta de apoio social e de apoio financeiro. Os autores sugerem que aos grupos vulneráveis deve ser oferecido apoio psicológico em termos de aconselhamento online e/ou grupos de apoio.

$\mathrm{Na}$ Espanha, estudo realizado por GarcíaÁlvarez, De La Fuente-Tomás, García-Portilla et al. (2020) durante o lockdown, revelou que entre pessoas que não tem antecedentes de transtorno mental, o fato de ser do sexo feminino representa por si só um risco mais elevado para o sofrimento psicológico. No entanto, independentemente do sexo, o avançar da idade diminui o risco de depressão ou de estresse e aumenta o risco de pensamentos intrusivos. O estudo sugere que o aproveitamento do tempo livre pode ser uma estratégia de proteção contra a ansiedade, o estresse, os pensamentos intrusivos e a evitação, mas não contra a depressão.

Bu, Steptoe e Fancourt (2020) verificaram, em estudo realizado no Reino Unido, que pessoas com diagnósticos de transtornos mentais pré-existentes, adultos jovens, mulheres e estudantes corriam maior risco de vivenciar altos níveis de solidão; mas certos fatores sociais, como morar com outras pessoas, ter amigos próximos e ter forte apoio social percebido foram apontados como elementos de proteção.

Estudos mostram ainda que a insônia, a ansiedade e a frustração relacionadas à COVID-19 foram fatores de risco para o aumento do sofrimento psicológico, enquanto hábitos de sono saudáveis e otimismo foram vistos como fatores de proteção. (YAMAMOTO; UCHIUMI; SUZUKI et al., 2020) Estudo realizado na Itália revelou haver uma relação significativa entre a qualidade do sono, a ansiedade generalizada e o sofrimento psicológico com sintomatologia do transtorno de estresse pós-traumático (TEPT) relacionados à COVID-19. (CASAGRANDE; FAVIERI; TAMBELLI et al., 2020)

$\mathrm{Du}$, Mayer, Hummel et al. (2020) observaram que algumas estratégias de enfrentamento, como expressar emoções, consumir bebidas alcoólicas ou limitar-se a receber informações sobre a COVID-19 durante o lockdown aumentaram a incidência de sintomas de depressão, de ansiedade e de estresse. Por outro lado, estratégias ativas para lidar com a ansiedade moderada a extremamente grave, como tomar medidas de proteção e adquirir melhor conhecimento, foram mais benéficas; contudo, a estratégia mais eficaz foi focar no enfrentamento mental, como técnicas de relaxamento e a obtenção de conhecimentos sobre saúde mental.

Estudo realizado na Itália, com o objetivo de documentar a evolução do sofrimento psicológico durante o lockdown, revelou que indivíduos que se empenharam em estratégias ativas e flexíveis em situações estressantes apresentaram menos sintomas depressivos. (ROMA; MONARO; COLASANTI et al., 2020)

Burhamah, AlKhayyat, Oroszlányová et al. (2020) verificaram, em estudo realizado no Kuwait, com 4.132 pessoas, uma baixa incidência de sintomas de ansiedade. Os autores sugerem que estes resultados possivelmente estejam associados às estratégias de apoio psicológico empregadas naquele país, as quais podem ter contribuído para evitar a angústia causada por informações falsas. Entre essas estratégias os autores destacam o lançamento de um site online com oferta de sessões gratuitas de aconselhamento psicológico, vídeos educacionais focando os mecanismos de enfrentamento da ansiedade e do estresse e informações sobre o vírus e os métodos de prevenção para reduzir a sua transmissão.

Entre as iniciativas praticadas no Brasil, destacase a publicação, em 26 de maio de 2020, da Resolução ${ }^{\circ}$ 4/2020 do Conselho Federal de Psicologia, autorizando a prestação de serviços psicológicos remotos a pessoas e grupos em situação de urgência, emergência e desastre, bem como de violação de direitos ou violência, visando atenuar as implicações psicológicas diante da COVID19. (SCHMIDT; CREPALDI; BOLZE et al., 2020)

Fernández, Crivelli, Guimet et al. (2020) apontam para o papel da mídia e dos formuladores de políticas públicas no desenvolvimento de estratégias de comunicação, recomendações e programas de saúde mental com a finalidade de diminuir o medo da população e prepará-la para a adoção de melhores formas de enfrentamento.

Nessa perspectiva, estudos ressaltam a necessidade de se empregar, a nível global, medidas de saúde que tenham como foco também o impacto da pandemia na saúde mental, entre as quais podem ser citadasintervençõespsicológicasdeapoio, sobretudopara lidar com aqueles estressores psicossociais relacionados ao isolamento/quarentena, o medo e a vulnerabilidade. (TORALES; O'HIGGINS; CASTALDELLI-MAIA et al., 2020)

Smith, Twohy e Smith (2020) sugerem que, diante da crise atual e das sucessivas medidas de 
distanciamento social que estão em vigor em todo o mundo, a utilização de intervenções eficazes para aliviar os efeitos prejudiciais do isolamento social na saúde mental é uma estratégia imprescindível.

\section{Conclusão}

Este estudo permitiu verificar que a COVID19 é uma ameaça global à saúde, trazendo consigo sentimentos de medo, angústia e incertezas em relação ao futuro. Embora atualmente, no momento da conclusão deste trabalho, existam diversas vacinas disponíveis visando à redução da morbimortalidade causada pela doença, ainda é imperativo que se mantenha as medidas de prevenção, como a higienização constante das mãos, o uso de máscaras faciais e o distanciamento físico.

Medidas restritivas vêm sendo impostas pela grande maioria dos países desde o começo da pandemia com o objetivo de reduzir a disseminação do vírus e evitar o colapso do sistema de saúde. Tais medidas vieram transformar o modo de viver das pessoas, alterando rotinas e hábitos, como beijar, abraçar ou cumprimentar com aperto de mão, bem como a maneira de interação social, de trabalhar, de realizar atividades recreativas/lazer e de educação. Essas mudanças trouxeram consequências significativas à saúde mental das pessoas, colaborando para o aumento de sintomas depressivos, de ansiedade e de alterações na qualidade do sono.

Ficou evidente nos estudos pesquisados que as mulheres são as mais vulneráveis, apresentando níveis mais elevados de estresse, de ansiedade e de sintomas depressivos. Observa-se que a idade mais jovem também é um fator que está associado a níveis mais elevados de ansiedade, de angústia e de sintomas depressivos. Outras variáveis, como fatores socioeconômicos e nível educacional, tiveram particular influência na saúde psicológica e mental das pessoas durante as medidas de isolamento social. Alguns estudos revelaram ainda a influência negativa da mídia e das redes sociais no aumento do sofrimento psicológico.

Conclui-se que existe a necessidade de que sejam organizadas iniciativas de saúde pública direcionadas às populações mais vulneráveis, de forma que se possa reduzir a incidência de sofrimento psicológico decorrente da pandemia da COVID-19 e das consequentes medidas restritivas. Essas iniciativas devem ser pautadas levandose em conta uma abordagem integral que considere as dimensões físicas, mentais e sociais desses indivíduos.

\section{Referências}

AL-AJLOUNI, Y. A.; PARK, S. H.; ALAWA, J. et al. Anxiety And Depressive Symptoms Are Associated With Poor Sleep Health During a Period Of COVID-19-Induced Nationwide Lockdown: A Cross-Sectional Analysis Of Adults In Jordan. BMJ Open, v. 10, e041995, p. 1-10, Dez. 2020. Disponível em: https://pubmed.ncbi.nlm.nih.gov/33371040/. Acesso em: 21 de março de 2021 .

AZIZI, A.; ACHAK, D.; ABOUDI, K. et al. Health-Related Quality Of Life And Behavior-Related Lifestyle Changes Due To The COVID-19 Home Confinement: Dataset From a Moroccan Sample. Data Brief, v. 32, e106239, p. 1-10, Oct. 2020. Disponível em: https://pubmed.ncbi.nlm.nih. gov/32868996/. Acesso em: 24 de março de 2021.

BENKE, C.; AUTENRIETH, L. K.; ASSELMANN, E. et al. Lockdown, Quarantine Measures, And Social Distancing: Associations With Depression, Anxiety And Distress At The Beginning Of The COVID-19 Pandemic Among Adults From Germany. Psychiatry Res., v. 293: e113462, p. 1-9, Nov. 2020. Disponível em: https://pubmed.ncbi.nlm.nih.gov/32987222/. Acesso em: 09 de março de 2021.

BRASIL. Ministério da Saúde. COVID-19 - Painel Coronavírus. Disponível em: https://covid.saude.gov.br. Acesso em: 30 out. de 2020.

BU, F.; STEPTOE, A.; FANCOURT, D. Loneliness During A Strict Lockdown: Trajectories And Predictors During The COVID-19 Pandemic In 38,217 United Kingdom Adults. Soc Sci Med., v. 265, e113521, p. 1-6, Nov. 2020. Disponível em: https://pubmed.ncbi.nlm.nih.gov/33257177/. Acesso em: 23 de fev. de 2021

BURHAMAH, W.; ALKHAYYAT, A.; OROSZLÁNYOVÁ, M. et al. The Psychological Burden Of The COVID-19 Pandemic And Associated Lockdown Measures: Experience From 4000 Participants. J Affect Disord., v. 277, p. 977-985, Dez. 2020. Disponível em: https://www.ncbi.nlm.nih. gov/pmc/articles/PMC7476447/. Acesso em: 18 de fev. de 2021.

CASAGRANDE, M.; FAVIERI, F.; TAMBELLI, R. et al. The Enemy Who Sealed The World: Effects Quarantine Due To The COVID-19 On Sleep Quality, Anxiety, and Psychological Distress In The Italian Population. Sleep Med., v. 75, p. 12-20, Nov. 2020. Disponível em: https://www.ncbi.nlm.nih. gov/pmc/articles/PMC7215153/. Acesso em: 25 de março de 2021.

DELMASTRO, M.; ZAMARIOLA, G. Depressive Symptoms In Response To COVID-19 And Lockdown: A Cross-Sectional Study On The Italian Population. Sci. Rep., v. 10, e22457, p. 1-10, Dez. 2020. Disponível em: https:/www.nature.com/articles/s41598-020-79850-6. Acesso em: 15 de março de 2021.

DU, J.; MAYER, G.; HUMMEL, S. et al. Mental Health Burden In Different Professions During The Final Stage Of The COVID-19 Lockdown In China: Cross-Sectional Survey Study. J Med Internet Res., v. 22, n. 12, e24240, p. 1-12, Dez. 2020. Disponível em: https://pubmed.ncbi.nlm.nih. gov/33197231/. Acesso em: 11 de fev. de 2021.

DUARTE, M. Q.; SANTO, M. A. S.; LIMA, C. P. et al. COVID-19 e Os Impactos Na Saúde Mental: Uma Amostra Do Rio Grande do Sul, Brasil. Ciênc. saúde coletiva, Rio de Janeiro, v. 25, n. 9, p. 3401-3411, Sept. 2020. Disponível em: https://www.scielo.br/j/csc/a/ghSHWNYkP6gqJm4LQVhk $\mathrm{B} 7 \mathrm{~g} /$ ?lang=pt. Acesso em: 19 de março de 2021.

EVERY-PALMER, S.; JENKINS, M.; GENDALL, P. et al. Psychological Distress, Anxiety, Family Violence, Suicidality, And Wellbeing In New Zealand During The COVID-19 Lockdown: A Cross-Sectional Study. PLOS One, v. 15, n. 11, e0241658, p. 1-19, Nov. 2020. Disponível em: https:// pubmed.ncbi.nlm.nih.gov/33147259/. Acesso em: 20 de março de 2021.

FERNÁNDEZ, R. S.; CRIVELLI, L.; GUIMET, N. M. et al. Psychological Distress Associated With COVID-19 Quarantine: Latent Profile Analysis, Outcome Prediction And Mediation Analysis. J Affect Disord., v. 1, n. 277, p. 75-84, Dez. 2020. Disponível em: https://pubmed.ncbi.nlm.nih. gov/32799107/. Acesso em: 15 de fev. de 2021.

FIORILLO, A.; SAMPOGNA, G.; GIALLONARDO, V. et al. Effects Of The Lockdown On The Mental Health Of The General Population During The COVID-19 Pandemic In Italy: Results From The COMET Collaborative Network. Eur Psychiatry., v. 28, n. 63, e87, p. 1-11, Set. 2020. Disponível em: https://www.ncbi.nlm.nih.gov/pmc/articles/PMC7556907/. Acesso em: 21 de março de 2021.

GARCÍA-ÁlVAREZ, L.; DE LA FUENTE-TOMÁS, L.; GARCÍAPORTILLA, M, P. et al. Early Psychological Impact Of The 2019 Coronavirus Disease (COVID-19) Pandemic And Lockdown In A Large Spanish Sample. J Glob Health., v. 10, v. 2, e020505, p. 1-15, Dez. 2020. Disponível em: https://pubmed.ncbi.nlm.nih.gov/33110588/. Acesso em: 12 de março de 2021.

GUPTA, A. K.; SAHOO, S.; MEHRA, A. et al. Psychological Impact Of 
'Lockdown' Due To COVID-19 Pandemic In Nepal: An Online Survey. Asian J Psychiatr., v. 54, e102243, p. 1-2, Dez. 2020. Disponível em: https:// pubmed.ncbi.nlm.nih.gov/32619836/. Acesso em: 21 de março de 2021.

LIMA, R. C. Distanciamento E Isolamento Sociais Pela Covid-19 No Brasil: Impactos Na Saúde Mental. Physis., v. 30, n. 2, e300214, p. 1-10, 2020. Disponível em: https://www.scielo.br/j/physis/a/nyq3wrt8qpWFsSNpbgYX LWG/?lang=pt. Acesso em: 23 de março de 2021.

MASSAD, I.; AL-TAHER, R.; MASSAD, F. et al. The Impact Of The COVID-19 Pandemic On Mental Health: Early Quarantine-Related Anxiety And Its Correlates Among Jordanians. East Mediterr Health J., v. 26, n. 10, p. 1165-1172, Out. 2020. Disponível em: https://pesquisa.bvsalud.org/ global-literature-on-novel-coronavirus-2019-ncov/resource/pt/covidwho886696. Acesso em: 21 de fev. de 2021.

NOVOTNÝ, J. S.; GONZALEZ-RIVAS, J. P.; KUNZOVÁ, Š. et al. Risk Factors Underlying COVID-19 Lockdown-Induced Mental Distress. Front Psychiatry., v. 21, n. 11, e603014, p. 1-11, Dez. 2020. Disponível em: https://www.ncbi.nlm.nih.gov/pmc/articles/PMC7793642/. Acesso em: 24 de março de 2021.

PANDEY, D.; BANSAL, S.; GOYAL, S. et al. Psychological Impact Of Mass Quarantine On Population During Pandemics-The COVID-19 LockDown (COLD) Study. PLoS One., v. 15, n. 10, e240501, p. 1-10, Out. 2020. Disponível em: https://www.ncbi.nlm.nih.gov/pmc/articles/PMC7580982/. Acesso em: 14 de fev. de 2021.

PEREIRA, M. D.; OLIVEIRA, L. C.; COSTA, C. F. T. et al. A Pandemia De COVID-19, O Isolamento Social, Consequências Na Saúde Mental E Estratégias De Enfrentamento: Uma Revisão Integrativa. Research, Society and Development, v. 9, n. 7, e652974548, p. 1-35, Maio 2020. Disponível em: https://rsdjournal.org/index.php/rsd/article/view/4548. Acesso em: 15 de fev. de 2021.

RODRÍGUEZ-REY, R.; GARRIDO-HERNANSAIZ, H.; COLLADO, S. Psychological Impact And Associated Factors During The Initial Stage Of The Coronavirus (COVID-19) Pandemic Among The General Population In Spain. Front Psychol., v. 23, n, 11, e1540, p. 1-23, Jun. 2020. Disponível em: https://pubmed.ncbi.nlm.nih.gov/32655463/. Acesso em: 08 de março de 2021.

ROMA, P.; MONARO, M.; COLASANTI, M. et al. A 2-Month Follow-Up Study Of Psychological Distress Among Italian People During The COVID19 Lockdown. Int J Environ Res Public Health, v. 17, n. 11, e8180, p. 1-12, Nov. 2020. Disponível em: https://www.ncbi.nlm.nih.gov/pmc/articles/ PMC7663995/. Acesso em: 10 de março de 2021.

SCHMIDT, B.; CREPALDI, M. A.; BOLZE, S. D. A. et al. Saúde Mental E Intervenções Psicológicas Diante Da Pandemia Do Novo Coronavírus (COVID-19). Estud. Psicol., Campinas, v. 37, e200063, p. 1-13, Maio 2020. Disponível em: https://www.scielo.br/j/estpsi/a/L6j64vKkynZH9Gc4PtNW Qng/?lang=pt. Acesso em: 12 de março de 2021.

SHI, L.; LU, Z. A.; QUE, J. Y. et al. Prevalence Of And Risk Factors Associated With Mental Health Symptoms Among The General Population In China During The Coronavirus Disease 2019 Pandemic. JAMA Netw Open., v. 3, n. 7, e2014053, p. 1-16, Jul. 2020. Disponível em: https:// pubmed.ncbi.nlm.nih.gov/32609353/. Acesso em: 23 de março de 2021.

SILVA, H. G. N.; SANTOS, L. E. S.; OLIVEIRA, A. K. S. Efeitos Da Pandemia Do Novo Coronavírus Na Saúde Mental De Indivíduos E Coletividades. J. Nurs. Health., v. 10, n. esp., e20104007, p. 1-10, 2020. Disponível em: https://docs.bvsalud.org/biblioref/2020/06/1097482/4efeitos-da-pandemia-do-novo-coronavirus-na-saude-mental-de-i_fNxf8zd. pdf. Acesso em: 17 de fev. de 2021.

SMITH, B. M.; TWOHY, A. J.; SMITH, G. S. Psychological Inflexibility And Intolerance Of Uncertainty Moderate The RelationShip Between Social Isolation And Mental Health Outcomes During COVID-19. J Contextual Behav Sci., v. 18, p. 162-174, Out. 2020. Disponível em: https://www.ncbi. nlm.nih.gov/pmc/articles/PMC7489247/. Acesso em: 20 de fev. de 2021.

TORALES, J.; O'HIGGINS, M.; CASTALDELLI-MAIA, J. M. et al. The outbreak of COVID-19 coronavirus and its impact on global mental health. Int J Soc Psychiatry, v. 66, n. 4, p. 317-320, Jun. 2020. Disponível em: https://pubmed.ncbi.nlm.nih.gov/32233719/. Acesso em: 19 de março de 2021.

WATHELET, M.; DUHEM, S.; VAIVA, G. et al. Factors Associated With Mental Health Disorders Among University Students In France Confined During The COVID-19 Pandemic. JAMA Netw Open., v. 3, n. 10, e2025591, p. 1-13, Out. 2020.

WHO. Coronavirus Disease (COVID-19) pandemic. Disponível em: https://www.who.int/emergencies/diseases/novel-coronavirus-2019?gclid= Cj0KCQjw28T8BRDbARIsAEOMBczuUqljHx2CXKX7rtKKwt70mZUp z0URIJLMS2V Q5oPNs6XtL4BquUaAu4OEALw wcB. Acesso em: 30 out. 2020 .

YAMAMOTO, T.; UCHIUMI, C.; SUZUKI, N. et al. The Psychological Impact Of 'Mild Lockdown' In Japan During The COVID-19 Pandemic: A Nationwide Survey Under A Declared State Of Emergency. Int J Environ Res Public Health, v. 17, n. 24, e9382, p. 1-19, Dez. 2020. Disponível em: https://pubmed.ncbi.nlm.nih.gov/33333893/. Acesso em: 10 de jan. de 2021. 